\title{
LOS DERECHOS DE LA NATURALEZA: UN PASO ADELANTE, TRES ATRÁS
}

\section{THE RIGHTS OF NATURE: ONE STEP FORWARD, THREE STEPS BACKWARDS}

Resumen: El reconocimiento de la naturaleza como sujeto de derecho que hacen las constituciones de Ecuador 2008 y Bolivia 2009, representa un quiebre civilizatorio que hecha dárdos al corazón mismo del casi extinto Estado liberal moderno. Pese a ser resultado de un proceso social con una data de más de 15 años y no de algún movimiento ilustrado, la Constitución de Montecristi aporta a la teoría constitucional proponiendo nuevos vínculos entre moral y derecho y entre política y derecho, pero también creando nuevas instituciones que hacen posible la convivencia entre vivientes. En tal sentido, el reconocimiento constitucional es a la vez un diálogo y una ruptura con los marcos filosóficos y teóricos sobre los que se ha asentado la relación Estado-sociedadnaturaleza. Desde la segunda mitad del Siglo XX, se han dado dos grandes olas de reforma constitucional referidas a la Naturaleza. La primera que mata a la 'naturaleza' y entrona al 'medio ambiente', con el objeto de hacer posible la gestión de los recursos naturales. La seguna que revive de las cenizas a la 'naturaleza' y le otorga personalidad jurídica, para hacer posible el mundo de la vida. El reconocimiento de la naturaleza como sujeto de derechos se asienta en un proyecto societal que propugna un "biorepublicanismo", que rescata las visiones integrales, holísticas y comunitaristas, como ejes de la transformación de la sociedad. Como aspiración histórica, dicho reconocimiento tiene la virtud de reformular los parámetros morales y jurídicos sobre los que se asienta la relación Estado, sociedad y naturaleza.

Palabras claves: Derechos de la naturaleza. Sujeto de derecho. Deforma constitucional. Biorepublicanismo.

\begin{abstract}
The recognition of nature as subject of law made by the constitutions of Ecuador (2008) and Bolivia (2009) represents a break in civilization that hits directly to the heart of the almost-extinct modern liberal state. It is the outcome of a social process of more than 15 years, and not the result of any enlightened movement. However, the Montecristi Constitution contributes to the constitutional theory proposing new links between morality and law and between politics and law. Moreover, it creates new institutions that make possible the coexistence of living beings. Thus, the constitutional recognition of the legal personhood of nature is both a dialogue and a disruption with the philosophical and theoretical frameworks on which the State-society-nature relationship has been traditionally established. Since the second half of the 20th century, there have been two great waves of constitutional reform related to Nature. The first destroys the concept of "nature" and entronates "the environment" in order to make the management of natural resources possible. The second one revives from the ashes the concept of "nature" and gives it legal personhood, to make the world of life possible. The recognition of nature as a rights holder is based on a societal project that advocates a "biorepublicanism", which rescues the integral, holistic and communitarian views as axes to transform society. As a historical aspiration, this recognition has the virtue of reformulating the moral and legal parameters on which the relationship between State, society and nature is established.
\end{abstract}

Keywords: Rights of nature. Legal personhood. Subject of law. Constitutional reform. Bio-republicanism.

Recebido em 7 de abril de 2020

Avaliado em 22 de abril de 2020 (AVALIADOR A) Avaliado em 30 de setembro de 2020 (AVALIADOR B)

Aceito em 20 de outubro de 2020

\footnotetext{
1 Doctora en Derecho, Ciencia Política y Criminología pela Universitat de València; Doctora en Jurisprudencia y Abogada de la República por la Universidad Central del Ecuador; Profesora en el Instituto de Altos Estudios Nacionales; Avenida Amazonas N37-271 y Villalengua; https://orcid.org/0000-0003-3635-1462; ginachv2@yahoo.es
} 


\section{Introducción}

Vladimir Ilich Lenin (1904), escribió el ensayo "Un paso adelante, dos pasos atrás", que se transformaría en el fundamento de organización del Partido Bolchevique respondiendo, como sabemos, a la necesidad de efrentar el reformismo menchevique. De esta obra me interesa rescatar dos asuntos, uno simbólico y otro sustancial. El primero, relacionado con la importancia de retroceder estratégicamente frente a grandes obstáculos que se presentan, con el objeto de consolidar posiciones, sin perder la mira en el objetivo final. El segundo, que nos dice que el único camino que tienen los pueblos para resistir y vencer es su organización.

En el 2008, fruto de una Asamblea Constituyente, entró en vigencia una Nueva Constitución, que rediseñó el Estado ecuatoriano en sus fundamentos y fines. Declaró al Ecuador Estado constitucional de derechos y justicia, plurinacional e intercultural, a más de otros atributos de carácter democrático. ${ }^{2}$ Puso a los derechos de las personas, comunas, comunidades, pueblos y nacionalidades y a la naturaleza como fundamento y fin del Estado. ${ }^{3}$ Diseñó un sistema integral de garantías constitucionales para asegurar la vigencia material de los derechos. ${ }^{4}$ Estableció una institucionalidad pública sustentada en la participación y control ciudadano de la gestión y control social de lo público. ${ }^{5}$ Constitucionalizó el derecho, afirmando el valor normativo de la Constitución y el control constitucional de los actos de poder.

Para el constitucionalismo ecuatoriano, significó desarraigarnos del legicentrismo y formalimo jurídico que permaneció vigente durante toda su historia republicana, para incorporar, de entre las formulaciones más probadas del garantismo de raigambre europeo y anglosajón, así como de innovaciones propias, principios y reglas que tracen caminos de transformación.

Sin embargo, estos ajustes y actualizaciones duraron, como diría Sabina, lo que dura un invierno. Duraron el tiempo que persistieron las luchas contrahegemónicas, las resistencias frente a

\footnotetext{
2 El artículo 1 de la Constitución de la República del Ecuador (CRE) dice: El Ecuador es un Estado constitucional de derechos y justicia, social, democrático, soberano, independiente, unitario, intercultural, plurinacional y laico. Se organiza en forma de república y se gobierna de manera descentralizada.

La soberanía radica en el pueblo, cuya voluntad es el fundamento de la autoridad, y se ejerce a través de los órganos del poder público y de las formas de participación directa previstas en la Constitución.

Los recursos naturales no renovables del territorio del Estado pertenecen a su patrimonio inalienable, irrenunciable e imprescriptible.

3 Art. 10 de la CRE.- Las personas, comunidades, pueblos, nacionalidades y colectivos son titulares y gozarán de los derechos garantizados en la Constitución y en los instrumentos internacionales. La naturaleza será sujeto de aquellos derechos que le reconozca la Constitución.

4 Para garantizar los derechos, la Constitución establece garantías normativas (art. 84), garantías de políticas públicas (art. 85), y garantías jurisdiccionales (art. 86 al 94).

5 Art. 95 de la CRE.- Las ciudadanas y ciudadanos, en forma individual y colectiva, participarán de manera protagónica en la toma de decisiones, planificación y gestión de los asuntos públicos, y en el control popular de las instituciones del Estado y la sociedad, y de sus representantes, en un proceso permanente de construcción del poder ciudadano. La participación se orientará por los principios de igualdad, autonomía, deliberación pública, respeto a la diferencia, control popular, solidaridad e interculturalidad.

La participación de la ciudadanía en todos los asuntos de interés public es un derecho, que se ejercerá a través de los mecanismos de la democracia representativa, directa y comunitaria.
} 
las exigencias de la real politik, las rupturas con las demandas de la geopolítica regional y los recambios de poder que vinieron cargados de traiciones políticas, estrategias de lawfare e innombrables designios imperialistas.

En el caso del Ecuador, a los pequeños y grandes pasos que se dieron en los diez primeros años de vigencia de la Constitución, le siguieron dos, tres, quince, veinte, treinta pasos atrás, lo que nos dice que no basta con conquistar su texto si a este no le sigue el cambio cultural de su pueblo. Nos encontramos, en un punto en el que hablar de la Constitución ecuatoriana equivale casi hablar de un hecho del pasado; o si se prefiere en mejor tono, en el momento de asumir los retrocesos como oportunidades para consolidar posiciones, y recuperar otras. Intentaré lo segundo.

\section{El reconocimiento de los derechos de la naturaleza: la utopía como potencialidad del presente}

El Ecuador da un salto histórico al aprobar una Constitución que reformula elementos claves del Estado liberal clásico. Como resultado de un sui generis proceso de activación del poder constituyente, delinea un concepto de soberanía que incluye 'otras soberanías' -soberanía económica, alimentaria, energética ecológica ${ }^{6}$-, más allá de la territorial. Toma importantes recaudos institucionales y normativos para fortalecer la democracia en su carácter representativo, participativo y comunitario, buscando hacer efectivo el control ciudadano del poder público. Diseña un novedoso sistema de garantías de los derechos ciudadanos, que incluye el control de constitucionalidad de las políticas públicas que hasta ese momento se encontraba excento de control jurisdiccional, por entenderlo como dispositivo de gobernabilidad por excelencia. Entre otras tantas novedades.

Siendo el resultado de un amplio proceso social, con una data de más de 15 años, la Constitución de Montecristi ${ }^{7}$ aporta a la teoría constitucional proponiendo nuevos vínculos entre moral y derecho, y entre política y derecho, pero también creando nuevas instituciones que hacen posible la convivencia entre diferentes formas de economía (de mercado, pública, social y soliaria), así como creando nuevos derechos. Entre estos últimos, el inciso 2 del artículo 10 establece que: "Las personas, comunas, pueblos, nacionalidades y colectivos son titulares y gozarán de los derechos garantizados en la Constitución y en los instrumentos internacionales"; y a renglón seguido determina: "La naturaleza será sujeto de aquellos derechos que le reconozca la Constitución". Más adelante y refiriendose a los derechos del Buen Vivir, el Capítulo Séptimo "Derechos de la Naturaleza", en cuatro artículos, traza el contenido de los derechos garantizados.

\footnotetext{
6 Artículos constitucionales: 281 sobre la soberanía alimentaria; 283 sobre la soberanía económica; 284, sobre la soberanía energética; 400 soberanía sobre la biodiversidad.

7 Así denominada por el lugar en donde se reunió la Asamblea Constituyente. Montecristi es un cantón de la provincia costera de Manabí, famoso porque ahí se originaron los denominados "Pamana Hats", pero sobre todo por ser el lugar de nacimiento del General Eloy Alfaro, quien lideró y consolidó la revolución liberal de finales del siglo XIX y comienzos del $\mathrm{XX}$, y quien, además, fue pionero en comercializar el famoso sobreros.
} 
Desde la prescripción normativa, la naturaleza o Pacha Mama, "tiene derecho a que se respete integramente su existencia y el mantenimiento y regeneración de sus ciclos vitales, estructura, funciones y procesos evolutivos." También tiene derecho a la restauración, para lo cual se otorgan amplias facultades tanto a la ciudadanía para actuar en su defensa, como al Estado para garantizar la vigencia del derecho. ${ }^{8}$ Se trata por tanto de un derecho objetivo que establece deberes y obligaciones a ser observadas por el Estado y la sociedad.

El reconocimiento constitucional implica otorgar un valor en sí a la naturaleza, independientemente del conjunto de intereses o necesidades humanas. Exije asumir una responsabilidad estatal respecto de su existencia, así como de sus ciclos vitales, estructura, funciones y procesos evolutivos. Compromete a la ciudadanía y a los entes estatales en su restauración y preservación. En tal sentido, el reconocimiento constitucional es, a la vez, un diálogo y una ruptura con los marcos filosóficos y teóricos sobre los que se ha asentado la relación Estado-sociedad-naturaleza.

Las disposiciones referidas, vistas desde la estructura de la Constitución, hacen parte de un proyecto de país que concibe de manera integral e interrelacionada el conjunto de niveles, dimensiones y grados de relación entre estructuras humanas y no humanas. Con esto me refiero a que los derechos de la naturaleza, tal como los derechos humanos constitucionalmente reconocidos, marcan los fines del Estado, esto es, su sentido teleológico, el mismo que se apalanca en tres grandes pilares: 1) el régimen de desarrollo concebido como un sistema participativo en donde se resguardan varias nociones de soberanía como la soberanía ecológica, alimentaria, energética y económica; 2) el Buen Vivir, ${ }^{9}$ esto es, el conjunto de condiciones que hacen posible la calidad de vida de las personas, comunidades, pueblos y nacionalidades, y de la naturaleza; entendiendose como tales a: la educación, salud, seguridad social, hábitad y vivienda, cultura, cultura física y tiempo libre, comunicación social, ciencia y tecnología, población y movilidad humana, seguridad humana, transporte, así como a la biodiversidad y los recursos naturales; 3) la integración latinoamericana ${ }^{10}$ marcada por la cooperación Sur-Sur y la promoción del manejo sustentable del patrimonio natural, la cooperación y complementación energética, la conservación de la biodiversidad, los ecosistemas y el agua, el desarrollo científico y tecnológico y la implementación de estrategias de soberanía alimentaria.

Una Constitución en este sentido ubica al Cuerpo iuris constitucional en el campo de lo que el profesor De Cabo define como "constitucionalismo del conflicto", esto es, un constitucionalismo que apunta a:

\footnotetext{
8 Artículos 71 al 74 de la CRE.

9 No obstante el Título VII de la Constitución establece el Régimen del Buen Vivir, desarrollado en los artículos que van del 340 al 415, las referencia al buen vivir se encuentran de manera transversal a lo largo del texto constitucional.

${ }^{10}$ Es notable la importancia que la Constitución brinda a la integración latinoamericana, al dedicarte el Capítulo Tercero, del Título VIII de las Relaciones Internacionales, que delinea un cuidadoso esquema de relacionamiento en materia económica, ambiental, de armonización legislativa, de promoción de la cultura y de la ciudadanía latinoamericana y caribeña, la seguridad regional y el fortalecimiento de la institucionalidad integracionista (art. 423 CRE).
} 
... la destrucción de las apariencias sobre el orígen y función del derecho, de especial importancia por su utilización como elemento legitimador; ser el derecho del conflicto respecto del que actúa como 'derecho de parte'; e implicar un desbloqueo de la razón jurídica, liberándola del positivismo, con todas sus implicaciones, abriendo, por tanto, todas las posibilidades para el cambio social (Tapia \& De Cabo, 2016, p. 185).

Con una marcada vocación participacionista, la Constitución busca reformular las relaciones entre ecomía y política, de tal manera que el orden económico no sea visto únicamente como categoría técnico-económica sino que sea parte de las dinámicas sociales y políticas que deban resolverse en términos democráticos, considerando, por ejemplo, la necesidad de encontrar soluciones reales al endémico problema de las desigualades, o adoptando medidas objetivas y concretas para organizar la defensa de 'los bienes comunes'. ${ }^{11}$

De esta manera, una herética utopía cobrará vida desafiando al sacrosanto antropocentrismo, Gran Espíritu civilizatorio del mundo occidental, abriéndose camino como potencialidad del presente.

\section{El derecho como campo de disputa}

A las constituciones que se plantean una reformulación de la relación entre Estado-sociedadnaturaleza, les ha tocado bucear en un agitado y convulso mar de políticas y normas ambientales de carácter global, regional y local, marcadas por visiones economisistas que tempranamente, desde la Conferencia de Estocolmo de 1972, transformaron la naturaleza en ambiente.

Lo que ha variado desde entonces son los énfasis en la gestión del ambiente, en donde los gobiernos fueron tomado mayor protagonismo (aunque no siempre ha sido favorable al ambiente). En donde también se amplió la capacidad regulatoria del Estado en la materia, se han destinado fondos para programas estatales y no estatales, se han celebrado pomposas conferencias internacionales, y operan un sinnúmero de grupos de trabajo en organismos internacionales y regionales, a más de contar con una basta jurisprudencia nacional y de cortes internacionales.

Las "políticas del ambiente" que surgen de esta dinámica internacional y global, y que en términos generales son diseñadas por "grupos de expertos" vinculados a algún organismo internacional, cuando no a una corporación transnacional, vienen por lo general acompañadas de la necesidad de emprender procesos de reformas normativas, sea a nivel legal o constitucional.

La primera ola de constitucionalización de los derechos ambientales ocurrirá en Latnoamérica entre los años 70 y 80, y se caracterizó por reconocer el derecho humano al medio ambiente libre de contaminación. De acuerdo a Brañes (2001, p. 12), entre 1972 y 1999, 16 de los 20 países de la región que se dieron nuevas constituciones, incorporaron importantes preocupaciones

\footnotetext{
${ }^{11}$ El Título VI, Régimen de Desarrollo, concreta la idea planteada, en el primer inciso del artículo 275 que establece: "E1 régimen de desarrollo es el conjunto organizado, sostenible y dinámico de los sistemas económicos, políticos, socioculturales y ambientales, que garantizan la realización del buen vivir, del sumac kawsay." Esta concepción integral del desarrollo se delinea en los artículos de la Constitución que van del 275 al 339.
} 
de la sociedad latinoamericana, entre las que se cuentan disposiciones referidas a la protección del medio ambiente y la promoción de un modelo de desarrollo sostenible; lo que en palabras del autor, vinieron a "enverdecer" las Leyes Fundamentales. ${ }^{12}$

En el caso ecuatoriano, la Constitución de 1979 reconoció, en el segundo inciso del artículo 19:

El derecho a vivir en un medio ambiente sano libre de contaminación. Es deber del Estado velar para que este derecho no sea afectado y tutelar la preservación de la naturaleza. La ley establecerá las restricciones al ejercicio de determinados derechos o libertades, para proteger el medio ambiente (Ecuador, 1979).

Más adelante, el artículo 50 determinaba que; "Para hacer efectivo el derecho a la vivienda y a la conservación del medio ambiente, las municipalidades podrán expropiar, reservar y controlar áreas para el desarrollo futuro de conformidad con la ley." ${ }^{13}$

Es posible encontrar las disposiciones constitucionales aquí aludidas también en la mayoría de constituciones que incorporaron el derecho al medio ambiente sano y libre de contaminación, añadiendo además disposiciones referidas al acceso y adecuada calidad del agua, el aire limpio de contaminantes que afecten a la salud, un suelo libre de contaminantes que afecten el disfrute de la vivienda, el equilibrio ecológico, la protección de la diversidad biológica, la prevención y remediación de los daños ambientales, a más de elementos procedimentales que garanticen la efectividad del derecho, como el derecho a la información, a la participación y el acceso a la justicia (Puentes, 2005, p. 444).

Los marcos legales y reglamentarios que derivan de las reformas constitucionales de esta época apuntan, sustancialmente, a implementar un esquema tecnocrático de gestión, manejo, uso y preservación del ambiente, que dicho sea de paso, siempre, o casi siempre, entra en pugna o contradicción con otras esferas de la gestión pública de los respectivos países, en especial, la económica, laboral, fiscal o financiera; en donde es fácil predecir quien gana y quien pierde. No será sino hasta comienzos del siglo XXI que surgirá una segunda ola de reformas legales y constitucionales, que busca superar la visión antropocentrista del derecho al ambiente, y reconoce derechos a la naturaleza en términos de derecho objetivo.

En suma, desde la segunda mitad del Siglo XX, han existido, al menos, dos grandes olas de reforma constitucional ambiental. La primera que mata a la "naturaleza" y entrona al "medio

\footnotetext{
12 Así ocurrió con las Constituciones de Panamá (1972), Cuba (1976), Perú (1979, sustituida en 1993), Ecuador (1979, sustituida en 1998), Chile (1980), Honduras (1982), El Salvador (1983), Guatemala (1985), Haití (1987), Nicaragua (1987), Brasil (1988), Colombia (1991), Paraguay (1992), Argentina (1994), República Dominicana (1994) y Venezuela (1999). Doce de estas dieciséis Constituciones fueron promulgadas entre 1972 y 1992, estos es, en el período de veinte años que medió entre la Conferencia de Estocolmo y la Conferencia de Río (Brañes, 2001, p. 12).

${ }^{13}$ Las reformas constitucionales de 1993 y la Constitución de 1998 (Asamblea Nacional Constituyente, 1998), incorporaron otros elementos de protección del medio ambiente como la noción de manejo sustentable de los recursos naturales, la participación de los pueblos indígenas en el uso, usufructo, administración y conservación de los recursos naturales que se hallen en sus tierras; compensaciones a residentes de áreas protegidas afectados por las limitaciones a sus derechos constitucionales; entre otras.
} 
ambiente" con el objeto de hacer posible la gestión de los recursos naturales. La segunda que le vuelve a dar aliento a la "naturaleza" otorgándole personalidad jurídica, para hacer posible el mundo de la vida. Pero, żqué significa en términos jurídicos reconocer derechos a la Naturaleza? Para buscar respuestas a este interrogante, conviene traer las palabras del profesor Ferrajoli (2004), cuando sostiene que la constitucionalización rígida de los derechos sirven para injertar una dimensión sustancial no solo en el derecho sino también en la democracia, lo cual queda de manifiesto al observar que

\footnotetext{
... las dos clases de normas sobre la producción jurídica -las formales, que condicionan la vigencia, y las sustanciales que condicionan la validez- garantizan otras tantas dimensiones de la democracia: la dimensión formal de la <democracia política $>$, que hace referencia al quien y al cómo de las decisiones y que disciplinan las formas de las decisiones; y la dimensión sustancial o material, que se refiere al qué es lo que no puede decidirse o debe ser decidido por cualquier mayoría, y que está garantizado por las normas sustancialales que regulan la sustancia o el significado de las mismas decisiones, que quedan vinculadas al respeto de los derechos fundamentales y demás principios axiológicos (Ferrajoli, 2004, p. 23).
}

Del planteamiento de Ferrajoli se puede deducir al menos dos cuestiones que nos ayudan a encontrar las primeras respuestas a nuestro interrogante: 1) que cuando se habla de los vínculos de sustancia siempre nos referiremos, al menos hasta el momento, a aquellos atienentes a la dignidad humana; esto es, excluyendo de tal condición sustancial a las cosas o a los seres vivos no humanos. 2) que una vez reconocido en términos de valor a los seres vivos no humanos, estos quedan integrados a los vínculos de sustancia del Derecho, y en consecuencia, inciden en los aspectos formales y sustanciales de la producción jurídica. En esto consiste la gran ruptura que suscita la Constitución de Montecristi respecto de la estructura sustancial de los derechos, pero también de la democracia; ruptura que se enmarcada en un pensamiento crítico que propone una reconfiguración de la tradicional relación entre Estado-sociedad y naturaleza, buscando superar las visiones economisistas y de dominación que se mantiene frente a ella.

\section{Las potencialiades del presente: transitar hacia el ecologismo profundo}

Advertidos los cambios y transformaciones jurídicas, pasamos a referirnos a los debates teóricos que han acompañado las transformaciones normativas aquí anotadas, en tanto otorgan sentido y dan coherencia a su contenido.

De la misma manera como observamos dos grades olas de reformas legales que incorporaron al plexo normativo constitucional el ambiente y la naturaleza, Zaffaroni (2019, p. 69) nos advierte de dos grandes vertientes de pensamiento que enfocan sus reflexiones teóricas a dichos temas: una vertiente de ecologismo ambiental que tiene al humano como titular de los derechos y una de ecologismo profundo que le reconoce personería a la naturaleza, como titular de derechos propios, con independencia del humano. 
Coincidiendo con este planteamiento, cabe recordar que el discurso liberal del desarrollo sostenible surge en el marco de la crisis de la deuda externa, y la crisis social y económica de los 70s que esta provoca, lo que para los países dependientes significó aumento del desempleo, pobreza y conflictividad social; mientras que para los países desarrollados, la crisis del dólar y el aumento del precio del petróleo provocó la desestabilización de sus economías, abriendo un período de fuerte recesión que se extenderá a los años 80 .

Así las cosas, el debate ambiental que arranca con la Conferencia de Estocolmo de 1972, surge como un discurso capaz de renovar los compromisos internacionales y sociales en torno al interés común por la conservación del medio ambiente, las necesidades del desarrollo, la equidad intergeneracional y la pobreza. Esta problemática que quedó fijada en el estudio Los límites del crecimiento, de 1972, realizado por encargo del Club de Roma, alerta de los peligros del crecimiento continuado. Más tarde, la Comisión Mundial del Medio Ambiente y Desarrollo, basada en el Informe Bruntland Nuestro Futuro Común, de 1987, asumirá oficialmente el concepto de desarrollo sostenible, ${ }^{14}$ marcando la línea base para los estudios y las políticas que se desarrollen a su amparo.

Entre los numerosos estudios académicos, informes técnicos y de grupos de trabajo que se realizaron sobre el tema, el estudio de Sotelsek y Ahamdanech (2001, pp. 154-155) deja claro que la tesis del desarrollo sostenible plantea soluciones a los problemas del medio ambiente, el desarrollo, la equidad intergeneracional y la pobreza, proponiendo una idea de crecimiento que permita satisfacer las necesidades actuales sin comprometer la capacidad de las futuras generaciones, mientras que para enfrentar los problema de pobreza propone la idea de complementariedad y/o sustitución entre el capital físico (humano y no humano) y natural. La solución para impulsar el desarrollo sustentable tiene que ver con incorporar las variables ambientales a la función de producción, establecer la valoración monetaria del stock ambiental y generar capital a partir de las rentas obtenidas de la extracción de recursos no renovables.

Entre la crisis económica de las décadas de los 70s y 80s, y las propuestas ambientalistas marcadas por la idea del desarrollo sustentable, los discursos oficiales giraban alrededor de dos grandes ideas: que el crecimiento económico era necesario para erradicar la pobreza, y que el problema ambiental tiene que ver con las actividades "depredadoras" de los pobres y no con las necesidades del crecimiento. Como numerosos estudios lo refieren, en las últimas décadas del Siglo XX, desde las posiciones oficiales se culpó de la crisis ecológica a los pobres del Tercer Mundo, a las políticas de acceso mundial a los recursos naturales, a la contaminación global y a los estilos de vida de los ricos del Norte. Una buena parte de los estudios críticos se enfocarán en responder y contra argumentar las tesis oficialistas, así como en denunciar la implementación de un capitalismo ambiental.

\footnotetext{
${ }^{14}$ Del mar de estudios, informes, análisis, definiciones del concepto e interpretaciones acerca del tema, resalto dos que considero marcaron el debate de al menos las dos siguientes décadas: el estudio de Gallopín (2003), que plantea los marcos analíticos que le servirán a la CEPAL para monitorear el desarrollo del tema. Y el trabajo de Gudynas (2003, p. 43), que propone una lectura crítica del concepto de desarrollo sostenible, los enfoques, las acciones y actores partes de este nuevo discurso económico, y que tuvo una importante repercusión en el debate ambiental.
} 
Frente a estas posturas que adquirieron estatus de discurso "políticamente correcto", los estudios culturalistas de la década de los 80 s, pusieron a debate el tema de la objetivación de la naturaleza por la ciencia moderna y de la visión reduccionista que la entiende como recurso natural al servicio de las economías de mercado. Pusieron también en evidencia el despliegue ideológico capitalista que, de acuerdo a Escobar (1995, p. 12), impulsó el consumismo bajo el postulado de la escasez, la explotación de los occidentales a los no occidentales, la acelerada destrucción de los entornos biofísicos y el tratamiento de la naturaleza como mercancía; lo que sirvió para implantar la idea instrumental de que lo que circula no es vida sino recursos. Así la naturaleza es reducida a un mero apéndice del ambiente, y con ello se declara su muerte simbólica.

En la misma línea de confrontación al ambientalismo capitalista, las críticas que desde visiones ecosocialistas se hacen a la "fase ecológica" de la economía capitalista, hablan de la importancia de comprender lo que J.O'Connor (1988, 1991 como citado en Escobar, 1995, p. 14) considera una segunda contradicción del capitalismo, que desplaza la contradicción entre fuerzas productivas y relaciones de producción por la contradicción derivada de la capitalización progresiva de las condiciones de producción, esto es, de la capitalización de todo elemento que es tratado como una mercancía aunque no se produzca como tal (la fuerza de trabajo, la naturaleza, el mercado, p.e.). Esta tesis se ha hecho más vigente a medida que avanza la fase del neoliberalismo especulativo que transitamos.

Desde la ecología política o ecología de los pobres, Gudynas (2003, p. 57) abre un importante campo de análisis al defender el rol de las poblaciones locales en el sostenimiento de los entornos naturales y la biodiversidad, poniendo el énfasis en las disputas por la apropiación de bienes comunes de la naturaleza. Los planteamientos relacionados con el ecologismo de los pobres estuvieron acompañados en la década de los 90s, principalmente, por una efervescencia social marcada por diversas luchas: ambientalistas, ecodesarrollistas, feministas, etnicistas, caracterizadas por sostener discursos en contra de la destrucción de la vida, el cuerpo, la naturaleza y el espacio, y proclamando que la lucha contra la pobreza y la explotación son luchas ecologistas.

En la actualidad, una nueva ola ambientalista copa los debates políticos y teóricos, y tiene que ver con la crisis climática. La novedad en esta nueva ola es que el carácter movilizador en el tema ambiental ha dejado de tener como protagonistas a los grupos de expertos o a los movimientos sociales, y a dado paso a una suerte de ecologismo emocional (Antolín, 2019, p. 1), que en los hechos ha debilitando el ecologismo militante, y crea temores sobre su capacidad para confrontar el poder transnacional y global, causante y gestor de la actual crisis ambiental. ${ }^{15}$

\footnotetext{
${ }_{15}$ No es que el ambientalismo o ecologismo emocional haya estado ausente en el debate ambiental. Solo recordemos el impacto emocional que causó la divulgación de algunos discursos tales como el del jefe indio Noah Sealth al "hombre blanco" de 1854; el de la niña Severn Suzuki en la Cumbre de la Tierra de 1992; el de la premio nobel Wangari Maathai "Seré un colibrí"; la encíclica del papa Francisco "Laudato si", y tantos otros. La particularidad del ecologismo emocional postmoderno, estilo Greta Thunberg, hace referencia a esta conciencia ambiental o ecologista expresada en jóvenes que han alcanzado eco en redes sociales y eventos públicos programados por Ongs., al margen de las acciones colectivas o militantes, de los debates teóricos y los estudios científicos, y como resultado de sus propias experiencias individuales, y en mucho, del autoconocimiento adquirido a través de las redes sociales y programas de televisión. Las críticas que se vierten
} 
Fuera de las reflexiones de coyuntura, los análisis técnicos y los informes de expertos; estudios de raigambre filosófico y ético también han servido de sustento para configurar esta nueva relación Estado-sociedad-naturaleza, contenida en la Constitución ecuatoriana.

El profesor Zaffaroni sostiene que los fundamentos de lo que podríamos denominar como "ecologismo del Buen Vivir", se puden rastrear desde el siglo XVIII en una perspectiva filosófica y ética, sobre los derechos de los no humanos. Así, entre otros menciona a Aldo Leopold (1887-1948) y su Ética de la tierra; a Jeremy Bentham (1851-1939) y su línea utilitarista de la ecología profunda; o Henry Salt (1851-1939) y Los derechos de los animales. Ya en el Siglo XX, se menciona a Peter Singer (1975) y su Liberación animal; a Tom Regan (1983) sosteniendo que todo viviente debe ser considerado o tratado como un fin en sí mismo, y no sólo los dotados de conciencia moral, como pretendía Kant; a Hans Jonas (1903-1993) y su llamado a la responsabilidad y a la prudencia del humano frente a su propio dominio; a Michel Serres (1994) y su postulado de que desde Hiroshima y Nagasaki, el humano ha descubierto una nueva muerte: la muerte de la especie, frente a la cual plantea realizar un nuevo contrato: el contrato con la naturaleza, para evitar nuestra propia extinción. También se alude a los científicos que sostienen la hipótesis Gaia, entre ellos, James Lovelock (1993), que plantea entender al planeta como un ente viviente, no en el sentido de un organismo o un animal sino en el de un sistema que se autorregula; y Maturana y Varela y su tesis de los sistemas autopoiéticos (Zaffaroni, 2019, p. 71-82).

A este conjunto de pensadores podemos sumar a Paul Crutzen y Eugene Stoermer que en el 2000 acuñaron el término "Antropoceno" para describir la época actual en la que los humanos han tenido un enorme impacto en el medio ambiente que llega a niveles geológicos, alertando sobre la necesidad de abandonar nuestro dominio sobre la economía y sobre la naturaleza.

\section{La opción por el biorepublicanismo del Buen Vivir}

Las acciones gubernamentales, centradas en una visión sectorial de la gestión del ambiente, han tenido dificultades para traducir las perspectivas de integralidad, intergeneracionalidad, bien común y justicia ambiental, a políticas ambientales que consoliden dichos horizontes. Demandadas, o cooptadas, por lógicas de capitalismo ambiental, son más eficientes en las tareas de regulación del campo, conservación de áreas naturales o generación de información técnica, que en las tareas de prevención, control y corrección de los actos que atentan al ambiente. Las soluciones de mercado como la venta de oxígeno, los servicios ambientales, el manejo sustentable de áreas y la gestión del ambiente, si bien han paliado algunos problemas, se han caracterizado por postergar la adopción de medidas encaminadas a corregir las causas objetivas del deterioro ambiental y social, que tienen

al ecologismo emocional tienen que ver con la sospecha sobre el poder que pueda tener esta modalidad de resistencia frente al poder transnacional responsable de la crisis ambiental contemporánea. 
que ver con el sostenimiento de sistemas de poder basados en nociones de crecimiento ilimitado, apropiación de la renta, consumismo, especulación financiera y depredación de la naturaleza.

Mientras tanto, las tesis del ambientalismo y el ecologismo crítico han sido valiosas para evidenciar las contradicciones y limitaciones del ambientalismo capitalista, así como para incorporar al debate elementos centrales como la conflictividad social, los fundamentos de la crisis ambiental y el carácter político de las luchas ambientales; no obstante, muchas parecen no salir del juego neoliberal que coloca en el centro del debate a la economía y a las necesidades de desarrollo del capitalismo gobal, y terminan sucumbiendo en la trampa de crear una falsa disyuntiva entre justicia social y justicia ambiental, llevando el diálogo a imposibilidades tanto para garantizar los derechos de la naturaleza como para superar la pobreza y potenciar el desarrollo.

Frente a este panorama, lo "nuevo" se encuentra en los programas políticos de los gobiernos progresistas latinoamericanos, que proponen un renovado discurso respecto de la soberanía, los fines del Estado, el rol de lo público, la sujeción del poder a la constitución, la participación ciudadana, el garantismo de derechos, el desarrollo marcado por el Buen Vivir ecuatoriano, o el Vivir Bien boliviano, la centralidad de los derechos de las personas, pueblos, colectivos, el ambiente y la naturaleza, y la integración latinoamericana. La Constitución ecuatoriana del 2008, por ejemplo, mantiene un diseño estructural que conecta, integra y proyecta cada parte con el todo. ${ }^{16}$

Lo "nuevo" también encontramos en varias de las políticas públicas que se aplicaron en dichas administraciones. El gobierno de Rafael Correa, por ejemplo, a contrapelo de las tesis neoliberales y de las visiones economisistas del ambiente, aplicó políticas económicas contracíclicas de carácter posdesarrollistas, que no solo repercutieron en la estructura económica del país, sino también en la configuración de esta nueva redefinición de la relación Estado-sociedad-naturaleza. Su lema "economía para la gente y no para el capital", se tradujo en políticas redistributivas que sacaron a más de dos millones de personas de la pobreza, en el mejoramiento del empleo y las condiciones laborales, en el desarrollo de infraestructura pública orientada al desarrollo interno y al cambio de la matriz productiva, así como en el impulso al conocimiento, la ciencia y la tecnología. Estas y otras políticas, que resulta extenso mencionar en este corto trabajo, reformulan el concepto de desarrollo sostenible que aborda los demás de medio ambiente, desarrollo, equidad intergeneracional y pobreza, bajo criterios de complementariedad y/o sustitución entre el capital físico y natural, desde lógicas de mercado.

La postura ambiental del presidente Correa, queda bastante bien expresada en el discurso que dio ante la $70^{\circ}$. Asamblea General de las NNUU de 2015, preambulo de la Cumbre Ambiental, en donde el mandatario expuso tesis que analistas la identifican como biorepueblicanismo del Buen

\footnotetext{
${ }_{16}$ Menciono como característica del diseño constitucional actual, porque no siempre ha sido mérito de las constituciones su coherencia interna. De la Constitución de 1998, por ejemplo, hay bastos estudios que demostraron su carácter esquizofrénico, en el sentido de que fue progresista en el reconocimiento de derechos, pero neoliberal en su funcionalidad política y económica, lo que llevó a que prevalezca lo segundo a costa de los primero, así como condujo a su sustitución por la Constitución del 2008.
} 
Vivir (Larrea Maldonado, 2011), o biosocialismo republicano (Ramírez Gallegos, 2010). Haciendo alución a las causas del deterioro ambiental, sostuvo que:

Por primera vez la pobreza no es fruto de la escasez de recursos o factores ambientales sino de sistemas económicos y de relaciones de poder perversos que potencian una insultante opulencia a la par que una indignante pobreza. . . . la mejor manera de reducir la pobreza es reducir las distancias sociales, territoriales, ambientales y culturales. ... Estas injustas relaciones de poder, afirmó, se ve a nivel global respecto de los problemas del cambio climático en el que los países en vías de desarrollo aportamos no más del $0.1 \%$ de las emisiones globales de carbono pero sufren los más graves efectos de dichas emisiones al ambiente.

En dicha intervención, terminó abogando por que "las Naciones Unidas apruebe una Declaración Universal de los Derehos de la Naturaleza en el que el principal derecho sea el que pueda seguir existiendo, pero también que pueda seguir ofreciendo los medios necesarios para que nuevas sociedades puedan seguir viviendo". Con esto llamaba a "asumir que el ser humano no es lo único importante de la naturaleza pero sigue manteniendo su grado de importancia", por lo que abogó por "asumir los desafíos del cambio climático con justicia social". Esta propuesta, que fue prionera en aquellos momentos, dió paso a un proceso de construcción de dicha Declaración ${ }^{17}$, que lleva ya varios años en proceso de elaboración.

El biorepublicanismo del Buen Vivir, plantea un modelo de Estado en donde la personalidad de la naturaleza reformula varias nociones filosóficas y éticas del pensamiento instrumental: comenzando por la noción de bien común que desplaza la centralidad del ser humano para compartir los beneficios del bien con todo lo viviente; la noción de sujeto, que más allá de reconocer a las personas ficticias o a los colectivos, reconoce a un sujeto sin referencia con el humano; la propia noción de ser humano como fin en sí mismo; la noción de dignidad humana, al reconocer dignidad a la naturaleza. En fin, la noción de desarrollo, al re-direccionarlo hacia el Sumak Kawsai, el Buen Vivir.

Amanera deconclusión, sostengo que una reformulación edificante de un constitucionalismo capaz de ofrecer salidas a los grandes problemas ambientales, económicos y sociales que enfrentan nuestras sociedades, es posible siempre y cuando se lo asuma como vía democrática para modifican de manera sustancial las relaciones de poder, las estructuras sociales y la cultura de la sociedad capitalista neoliberal. Es además viable, cuando gobernantes y gobernados se comprometen en la puesta en marcha de tales transformaciones.

En lo que atañe a los derechos a la naturaleza, más allá de las complicaciones que tiene bajar la norma constitucional a la realidad -tanto más cuando deben corregirse problemas seculares de inequidad-, tienen el potencial de transformar la naturaleza misma de las sociedades. En este sentido, un nuevo pacto basado en la voluntad del poder constituyente, en el reconocimiento integral

\footnotetext{
${ }_{17}$ El seguimiento del "Diálogo Interactivo sobre Armonía con la Naturaleza, en conmemoración del Día Internacional de la Madre Tierra", se puede realizar a través de la siguiente página electrónica de la Asamblea General de las Naciones Unidas: https://www.un.org/pga/73/es/2019/04/22/interactive-dialogue-on-harmony-with-nature-to-commemoratethe-international-mother-earth-day/
} 
y la garantía material de los derechos, en la interculturalidad como forma de relacionamiento social, en el manejo agónico de los conflictos y las diferencias; en el ejercicio de una democracia radical y un intervencionismo estatal socialmente justificado, hace posible pensar en una sociedad para los vivientes, humanos y no humanos, y no para el capital.

La Constitución ecuatoriana se adelantó a la historia, sin embargo, y siguiendo la compleja tradición del constitucionalismo ecuatoriano y sus 20 constituciones, presenciamos en la gestión gubernamental posterior a Correa un nuevo episodio de vaciamiento de su contenido. En donde los pasos que se dieron hacia adelante van retrocediendo, mientras se ha instalando un descarnado proyecto neoliberal que arraza con todo lo avanzado, y en el que no cabe la naturaleza como sujeto de derecho. Este nuevo repliegue estratégico deberá asumirse como el momento para acumular fuerzas sociales, teóricas e ideológicas que consoliden posiciones, asumiendo que el único camino que tienen los pueblos para resistir y vencer, y para construir el biorepublicanismo del Buen Vivir, es su organización.

\section{REFERENCIAS}

Antolín Iria, J. E. (2019, diciembre 24). El ecologismo en la época de la postpolítica. Del ecologismo militante al emocional: Límites estructurales del discurso ecologista. Ecología Política.

Asamblea Nacional Constituyente. (1998). Constitución del Ecuador.

Asamblea Nacional Constituyente. (2008). Constitución de la República del Ecuador.

Brañes, R. (2001). Informe sobre el desarrollo del derecho ambiental latinoamericano. Su aplicación después de diez años de la Conferencia de las Naciones Unidas sobre Medio Ambiente y el Desarrollo. PNUMA. http://centro.paot.org.mx/documentos/pnud/informe_derecho_ambiental.pdf

Ecuador (1979). Constitución del Ecuador. Plan de Reestructuración Jurídica del Estado.

Escobar, A. (1995). El desarrollo sostenible: Diálogo de discursos. Ecología Política. Cuadernos de Debate Internacional, (9).

Ferrajoli, L. (2004). Derechos y garantías. La Ley del más débil. Editorial Trotta.

Gallopín, G. (2003). Sostenibilidad y desarrollo sostenible: Un enfoque sistémico [Serie Medio Ambiente y Desarrollo. Proyecto "Evaluación de la Sostenibilidad en América Latina y el Caribe"]. CEPAL/Gobierno de los Países Bajos.

Gudynas, E. (2003). Ecología, Economía y Etica del Desarrollo Sostenible. Ediciones Abya Yala/ILDIS-FES.

Larrea Maldonado, A. M. (2011, abril-junio). El Buen Vivir como contrahegemonía en la Constitución ecuatoriana. Utopía y Práxis Latinoamericana, 16(53), 59-70. 
Lenin, V. I. (1904). Un paso adelante, dos pasos atrás. Fondo Documental EHK. http://archivo.juventudes.org/textos/Vladimir\%20Ilich\%20Lenin/un-paso-adelante-dos-atras-lenin.pdf

Puentes Riaño, A. (2005). Elementos de discusión acerca de la exigibilidad y justiciabilidad del ambiente como derecho humano. Instituto de Investigaciones Jurídicas de la UNAM. https://archivos. juridicas.unam.mx/www/bjv/libros/5/2469/26.pdf

Ramírez Gallegos, R. (2010). Socialismo del sumak kawsay: O Biosocialismo republicano [Documento de Trabajo No. 2]. Secretaría Nacional de Planificación y Desarrollo.

Sotelsk, D., \& Ahamdanech, I. (2001). Reflexiones sobre el crecimiento, el medio ambiente y la pobreza. Universidad de Alcalá. https://eco.mdp.edu.ar/cendocu/repositorio/00920.pdf

Tapia, D. C., \& De Cabo Martín, C. (2016, enero). "Aportes del constitucionalismo crítico". Estado \& comunes. Revista de políticas y problemas públicos, (2), 179-189.

Zaffaroni, E. R. (2019). La Pachamama y el humano. Ediciones Madres de Plaza de Mayo y Ediciones Colihue. 